Review

\title{
The Electrochemical Properties of Biochars and How They Affect Soil Redox Properties and Processes
}

\section{Stephen Joseph ${ }^{1,2,3, *}$, Olivier Husson ${ }^{4}$, Ellen Ruth Graber ${ }^{5}$, Lukas van Zwieten ${ }^{6,7}$, Sara Taherymoosavi ${ }^{2}$, Torsten Thomas ${ }^{8}$, Shaun Nielsen ${ }^{8}$, Jun Ye ${ }^{8}$, Genxing Pan ${ }^{3}$, Chee Chia ${ }^{2}$, Paul Munroe ${ }^{2}$, Jessica Allen ${ }^{1}$, Yun Lin ${ }^{1}$, Xiaorong Fan ${ }^{3}$ and Scott Donne ${ }^{1}$}

1 Discipline of Chemistry, University of Newcastle, Callaghan NSW 2308, Australia;

E-Mails: j.allen@newcastle.edu.au (J.L.); yun.lin@newcastle.edu.au (Y.L.); scott.donne@newcastle.edu.au (S.C.)

2 School of Materials Science and Engineering, University of NSW, Sydney NSW 2052, Australia; E-Mails: s.taherymoosavi@student.unsw.edu.au (S.T.); c.chia@unsw.edu.au (C.C.); p.munroe@unsw.edu.au (P.M.)

3 Institute of Resource, Ecosystem and Environment of Agriculture, Nanjing Agricultural University, Nanjing 210095, China; E-Mails: gxpan@njau.edu.cn (P.G.X.); xiaorongfan@njau.edu.cn (X.R.F.)

4 CIRAD/PERSYST/UPR 115 AIDA and AfricaRice Centre, 01 BP2031 Cotonou, Benin; E-Mail: husson@cirad.fr

5 Institute of Soil, Water \& Environmental Sciences, The Volcani Center, Agricultural Research Organization, P.O. Box 6, Bet Dagan 50250, Israel; E-Mail: ellen.graber@volcani.agri.gov.il

6 NSW Department of Primary Industries, Bruxner Highway, Wollongbar, 2480 NSW, Australia; E-Mail: lukas.van.zwieten@dpi.nsw.gov.au

7 Southern Cross Plant Science, Southern Cross University, Lismore, 2477 NSW, Australia

8 School of Biotechnology and Biomolecular Sciences, University of NSW, Sydney NSW 2052, Australia; E-Mails: t.thomas@unsw.edu.au (T.T.); shaunson26@gmail.com (S.N.); jun.ye2014@gmail.com (J.Y.)

* Author to whom correspondence should be addressed; E-Mail: joey.stephen@gmail.com; Tel./Fax: +61-243-695-108.

Academic Editor: Peter Langridge

Received: 28 May 2015 / Accepted: 13 July 2015 / Published: 21 July 2015

Abstract: Biochars are complex heterogeneous materials that consist of mineral phases, amorphous $\mathrm{C}$, graphitic $\mathrm{C}$, and labile organic molecules, many of which can be either electron donors or acceptors when placed in soil. Biochar is a reductant, but its electrical 
and electrochemical properties are a function of both the temperature of production and the concentration and composition of the various redox active mineral and organic phases present. When biochars are added to soils, they interact with plant roots and root hairs, micro-organisms, soil organic matter, proteins and the nutrient-rich water to form complex organo-mineral-biochar complexes Redox reactions can play an important role in the development of these complexes, and can also result in significant changes in the original $\mathrm{C}$ matrix. This paper reviews the redox processes that take place in soil and how they may be affected by the addition of biochar. It reviews the available literature on the redox properties of different biochars. It also reviews how biochar redox properties have been measured and presents new methods and data for determining redox properties of fresh biochars and for biochar/soil systems.

Keywords: biochar; cyclic voltammetry; Pourbaix diagram; electron shuttling

\section{Introduction}

Biochar is produced from the thermal treatment of biomass in the near absence of air. The utilisation of biochar in agriculture, forestry and land remediation has the potential to not only sequester carbon (C), increase plant yields and enhance soil chemical and physical properties, but also to alter emissions of nitrous oxide $\left(\mathrm{N}_{2} \mathrm{O}\right)$, affect nutrient leaching and run-off, impact the availability of contaminants in soil and alter soil physical and chemical properties [1]. Biochars are complex heterogeneous materials whose properties depend on feedstock and pyrolysis conditions. They consist of mineral phases, amorphous $\mathrm{C}$, graphitic $\mathrm{C}$, and labile organic molecules, many of which can be either electron donors or acceptors when placed in soil [2,3]. As a result, biochar can be both a reductant and oxidant [3]; its electrical and electrochemical properties are a function of both the temperature of production and the concentration and composition of the various redox active mineral and organic phases present [2-5].

When biochars are added to soils, they interact with plant roots and root hairs, micro-organisms, soil organic matter, proteins and the nutrient-rich soil solution to form organo-mineral-biochar complexes [4]. Redox reactions are hypothesized to play an important role in the development of these complexes, and also to cause significant changes in the original $\mathrm{C}$ matrix of the biochar [5].

Electrons are essential reactants in inorganic, organic, and biochemical reactions. While there is a fundamental link between proton transfer and electron transfer, redox reactions, i.e., transfer of electrons, are arguably more important to the chemistry and biochemistry of living systems than proton transfer reactions [5]. In the soil-rhizosphere-plant system, redox conditions play critical roles in cell and plant physiology, microorganism functioning and community structure, soil genesis, and nutrient availability, uptake and transformation, among other processes [5].

This paper reviews the redox processes that take place in soil and how they may be affected by the addition of biochar, a redox active material. It reviews the available literature on the redox properties of different biochars. It also reviews how biochar redox properties have been measured and presents new methods and data for determining redox properties of fresh biochars and for biochar/soil systems. 


\section{Review of Literature}

\subsection{An Overview of Redox Processes in Soils with Biochar}

Redox processes involving the donation and acceptance of electrons play an important part in soils, such as in nutrient cycling (phosphorous and nitrogen), scavenging of free radicals, formation and destruction of ethylene, methane and nitrous oxide [6,7]. Decomposing organic matter, including biochar, can be regarded as an electron-pump supplying electrons to more oxidised species present in the soil system [8]. However, unlike organic matter, biochar oxidises at much slower rates and has the potential to store electrons [9].

As Husson [10] notes, oxidation and reduction conditions are assessed by measuring the redox potential $(\mathrm{Eh} ; \mathrm{V})$. Eh is derived by combining the standard free energy change of the generic redox reaction in Equation (1) with the Nerst equation, where F is the Faraday constant, Ox is the oxidized species, Red is the reduced species, $\mathrm{R}=$ gas constant, $\mathrm{T}$ is temperature in kelvin, $n=$ number of electrons, $m=$ number of protons exchanged:

$$
\begin{gathered}
\mathrm{Ox}+\mathrm{mH}^{+}+\mathrm{ne}^{-} \rightarrow \text { Red } \\
E h=\mathrm{E}^{\circ}+\frac{\mathrm{RT} \times}{\mathrm{nF}} \frac{\ln [\mathrm{Red}]}{[\mathrm{Ox}]}+\frac{2.303 \mathrm{mRT} \times \mathrm{pH}}{\mathrm{nF}}
\end{gathered}
$$

The zero point for the Eh scale $\left(\mathrm{E}^{\circ}\right)$ is set by the standard hydrogen electrode (SHE). Equation (2) shows the relationship between $\mathrm{Eh}$ and $\mathrm{pH}$. As Eh is correlated to $\mathrm{pH}$, electron activity needs to be compared at a given $\mathrm{pH}$, which can be done by correcting Eh to $\mathrm{pH} 7$ using the regression given by Equation (2) [11,12]. As an example of the importance of this correction, a biochar suspension having an Eh of $500 \mathrm{mV}$ and $\mathrm{pH} 5$ has a higher electron activity than a biochar suspension having an Eh of $400 \mathrm{mV}$ and $\mathrm{pH}$ 9. Soil and biochar suspensions can be characterized simultaneously by their Eh and pH using a modified Pourbaix Diagram [4,8]. In the same way, the Eh-pH of a particular biochar suspension can be superimposed on this diagram. Examples are given and techniques are discussed in a latter section. The issue in measurement of the $\mathrm{Eh}$ and $\mathrm{pH}$ of these diagrams has been discussed in $[8,10]$.

Poise is the resistance to change in Eh when a small amount of oxidant removes electrons from a system or, conversely, a small amount of reductant adds electrons. Poise and Eh are expressions that can be compared to buffer capacity and $\mathrm{pH}$ in soils. Poise increases with the total concentration of oxidant plus reductant, and, for a fixed total concentration, it reaches a maximum when the ratio of oxidant to reductant is unity [13]. Since biochars function mainly as reductants, we suggest that, when added to soil, biochar may cause an increase in soil poise [10].

Molecular oxygen is the most common electron-acceptor species, although, in its absence, there are alternative electron acceptors in soil, such as $\mathrm{MnOOH}\left(\mathrm{E}^{\circ}=1.5 \mathrm{~V}\right), \mathrm{MnO}_{2}\left(\mathrm{E}^{\circ}=1.2 \mathrm{~V}\right)$, $\mathrm{NO}_{3}{ }^{-}\left(\mathrm{E}^{\circ}=0.88 \mathrm{~V}\right)$, and $\mathrm{Fe}^{3+}\left(\mathrm{E}^{\circ}=0.66 \mathrm{~V}\right)$ that can also cause oxidation of organic $\mathrm{C}$ [6]. Soil moisture status and soil structure are key factors controlling redox reactions. In well-aerated arable soils, there is a mosaic of anaerobic microsites, in particular in the rhizosphere, resulting from $\mathrm{O}_{2}$ consumption by both soil organisms and root respiration. Thus, there are two soil redox interfaces; namely (i) the low soil Eh rhizosphere zone, with a high Eh of surrounding well-aerated soil; and (ii) 
the low Eh rhizosphere region and its interface with the high Eh surfaces of live and growing roots. Similarly, when biochar is added to soil and adsorbs water, there will be internal pores that have no or very low concentrations of $\mathrm{O}_{2}$ and where the Eh is very low, as well as an area surrounding the biochar where the Eh can be high (in aerated soils [5]).

Redox transformations are most apparent at interfaces where there are two unlike environments and, hence, a driving force for reaction. Typically, these are wetlands, flooded fields and the regions between roots and moist soil in the rhizospheres of many plants [6]. Additions of high concentrations of biochar into the rhizosphere could introduce an environment that contrasts the one that would naturally develop there from the typical soil clays, silt, sand and organic matter components. The redox potential in the immediate area around the biochar particle could change as solutions rich in organic compounds, cations and anions, diffuse in and out of the macro- and meso-pores of the biochar. Joseph et al. [5] detailed biotic and abiotic reactions that could take place on the surface and in the pores of the biochar, with regards to both the $\mathrm{C}$ matrix and mineral matter.

Research has also highlighted the role that iron minerals play in redox processes in soil [7]. It has been hypothesised that iron minerals in biochar could catalyse a range of redox reactions associated with nutrient cycling, nitrification and denitrification [13]. Iron exists in all types of biomass both in the $\mathrm{Fe}^{2+}$ and $\mathrm{Fe}^{3+}$ oxidation states and both oxidation states can exist in the biochar usually as an iron oxide $\left(\mathrm{Fe}_{2} \mathrm{O}_{3}, \mathrm{Fe}_{3} \mathrm{O}_{4}, \mathrm{Fe}(\mathrm{OH})_{3}\right)$. The concentration of different Fe compounds with different oxidation states depends on the pyrolysis conditions (air is often entrained with fuel) as well as complex catalytic processes that take place during pyrolysis between the alkali metals and the organic molecules [5]. Some of these $\mathrm{Fe}$ phases have diameters less than $10 \mathrm{~nm}$ and are completely surrounded by $\mathrm{C}$, while others exist on the surfaces of pores and can be oxidised by air. Once biochars are placed in soil, Fe compounds can precipitate out on the surface of the biochar or, if they are in a water saturated environment, they can be reduced [4].

The redox processes involving Fe may include:

(1) Electron transfer from organic matter to $\mathrm{Fe}(\mathrm{III})$ (hydr) oxides via $\mathrm{C}$ oxidation [14].

(2) Reduction of $\mathrm{NO}_{3}{ }^{-}$to $\mathrm{NO}_{2}{ }^{-}$with the oxidation of $\mathrm{Fe}^{2+}$ to $\mathrm{Fe}^{3+}$.

(3) Mineralisation of organic $\mathrm{N}$ to $\mathrm{NH}_{4}^{+}$[15] and the oxidation of $\mathrm{NH}_{4}^{+}$to $\mathrm{NO}_{2}^{-}$with the consequent reduction of $\mathrm{Fe}^{3+}$ to $\mathrm{Fe}^{2+}$.

(4) Oxidation of $\mathrm{NH}_{4}{ }^{+}$to $\mathrm{NO}_{2}^{-}$with the consequent reduction of $\mathrm{Fe}^{3+}$, formation and oxidation of FeS minerals in the sulphur (S) cycle [7].

(5) Cycling of S from solid to soluble liquid species driven by oxidation or reduction of Fe species [7].

Biochar with a high content of Fe oxide nanoparticles at the surfaces of pores could significantly increase the rate of reduction of $\mathrm{NO}_{3}^{-}$and $\mathrm{NO}_{2}^{-}$by lowering the free energy required for the process [13].

Microorganisms can also actively modify and optimize their immediate geochemical surroundings by mobilizing nutrients for uptake and increasing the accessibility of electron acceptors for energy generation to facilitate assimilation and dissimilation [16]. $\mathrm{Fe}^{3+}$ educing microorganisms, such as the bacteria Shewanella sp., can excrete electrons to increase the availability of Fe minerals. For example, it was reported that small concentrations of biochar stimulate both the rate and extent of microbial reduction of the Fe(III) oxyhydroxide mineral ferrihydrite by Shewanella oneidensis MR-1 [17]. 


\subsection{The Electrochemical Properties of Biochars, Summary of Literature}

Only a handful of studies have measured redox characteristics of biochars. These are reviewed here. Unfortunately, none have yet explored in a well-controlled manner whether such properties actually play a role in the various effects biochars are reported to have on the soil environment, plant growth and health, gaseous emissions, and the makeup of the rhizosphere microbiome. This is a major knowledge gap.

Ishihara [18] reported that wood charcoal carbonised at $<300{ }^{\circ} \mathrm{C}, 300{ }^{\circ} \mathrm{C}-800{ }^{\circ} \mathrm{C}$ and $>800{ }^{\circ} \mathrm{C}$ acts as an insulator, a semiconductor and a conductor, respectively. Biochars produced at $600{ }^{\circ} \mathrm{C}$ and above are conductors but exhibit a lattice structure that contains a considerable concentration of micropores [19] and stable radicals within the graphitic structure. They contain very low concentrations of water-soluble organic molecules and oxygen-based functional groups. Both graphitic conductors and amorphous $\mathrm{C}$ semiconductors produced at temperatures above $600{ }^{\circ} \mathrm{C}$ are utilised in electrochemical devices (such as batteries, supercapacitors and microbial fuel cells) and there is now a considerable understanding of the electron transfer processes that take place at the surfaces both in biotic and abiotic redox reactions [20].

Mineral and $\mathrm{C}$ phases in biochar have different electrochemical potentials [21]. The $\mathrm{C}$ phase has a series of tubular pores (the xylem and phloem of the original biomass structure) that can connect the different mineral phases. These tubular pores are themselves porous at the nanometer scale, and there is also connectivity across the $\mathrm{C}$ phases. This porous structure can have similar properties to a semipermeable membrane, whereby two parallel $\mathrm{C}$ tubular pores with different concentrations of soluble metals can act as a galvanic cell [22]. Most biochars contain redox active Fe and Mn-based minerals, and many of these redox active minerals exist as nanophase particles [5] often in a number of oxidation states. For example, Fe oxide in biochar can exist as magnetite or hematite. Iron contents as high as $2.3 \%$ of the total weight of biochar (biosolids feedstock) has been reported [23], but wood-based biochars tend to have much lower concentrations $(0.14 \%-0.34 \% \mathrm{w} / \mathrm{w})$. However, biochars produced at lower temperatures $\left(<450{ }^{\circ} \mathrm{C}\right)$ have a much greater concentration of labile organic molecules and surface functional groups.

Graber et al. [2] found that aqueous extracts of biochars produced over a range of temperatures from three different feedstocks had substantial reducing capacities. Extracts of two biochars prepared from greenhouse wastes at two different highest heat temperatures (HTTs) were able to solubilize Mn and $\mathrm{Fe}$ from different soils over a wide range of $\mathrm{pH}$ values, presumably by means of reducing the oxidized metal species. The extract of the lower temperature biochar, having a greater variety and concentration of soluble reducing agents, solubilized more $\mathrm{Mn}$ and Fe than the extract of the higher temperature biochar. In the studied systems, the dissolved organic matter (DOM) fraction, in particular, phenolic compounds, was proposed to be responsible for the main part of the reducing capacity, which was on a par with the reducing capacities of various humic and fulvic substances.

Klupfel et al. [3] studied the redox properties of 19 wood and grass biochars produced at temperatures ranging from 200 to $700{ }^{\circ} \mathrm{C}$ using mediated electrochemical analysis. All the biochars could reversibly accept and donate up to $2 \mathrm{mmol}$ of electrons per gram of biochar, with the high mineral ash grass-based biochars having higher electron exchange capacities (EEC) than the wood-based biochars. Maximum EEC was found for biochars produced at $400{ }^{\circ} \mathrm{C}$. Combined 
electrochemical, elemental, and spectroscopic analyses of the thermosequence biochars provided evidence that the pool of redox-active moieties was dominated by electron-donating phenolic moieties in the low-HTT biochars, by newly-formed electron accepting quinone moieties in intermediate-HTT biochars, and by electron accepting quinones and possibly condensed aromatics in the high-HTT biochars.

It was also suggested that, due to its conductive properties, biochar solids promote direct interspecies electron transfer (DIET) in co-cultures of Geobacter metallireducens with Geobacter sulfurreducens or Methanosarcina barkeri in a fashion and extent similar to granular activated carbon (GAC), despite being 1000 times less conductive than GAC [9]. The possibility that DIET was promoted by the liquid soluble phase of biochar was rejected because an isolated soluble biochar fraction exhibited less DIET promotion than did the biochar together with the soluble phase. However, this may have been an artifact of the method used for isolating the soluble fraction, which differed from the method used to prepare the biochar itself and could have resulted in a much lower concentration of isolated soluble materials than would have been present in the biochar co-cultures. The authors reported that the reduced biochar was incapable of transferring electrons to Fe(III) citrate, leading them to conclude that electron transport through the solid biochars was unlikely to be due to quinone moieties, but rather, was due to the conductive properties of the solid phase itself. These results contradict those of [3], who found that all 19 studied biochars were able to reversibly donate and accept electrons. It also contradicts the study of [17]. Results from these few studies are insufficient to conclude the mechanisms involved in biochar redox activity, and clearly a gap in knowledge still exists.

\subsection{Measurement of the Electrochemical Properties of Fresh Biochars and Soil/Biochar Systems}

Different techniques have been used to measure the redox properties of biochars. This section reviews methods that have been published and presents new data using solid-state cyclic voltammetry (SSCV). Graber et al. [2] extracted the water-soluble organic fraction of biochars and used the Ferric Reducing Antioxidant Power (FRAP) assay to determine reduction capacity (RC) of the extracted organic molecules. Total phenols in the biochar aqueous extracts and DOM solutions were determined using the Folin Ciocalteu (F-C) assay. $\mathrm{FeSO}_{4} \cdot \mathrm{H}_{2} \mathrm{O}$ standards were also measured by the $\mathrm{F}-\mathrm{C}$ assay to calculate moles of charge transfer ( molc $_{\text {c }}$, where each mole of $\mathrm{FeSO}_{4}$ represents one mole of charge transfer. Solubilization of $\mathrm{Mn}$ and Fe from the soils were compared for biochar aqueous extracts and water as a function of $\mathrm{pH}$, which was controlled with a buffer.

Kluepfel et al. [3] finely ground the biochars, removed any $\mathrm{O}_{2}$ through purging with $\mathrm{N}_{2}$ at $80{ }^{\circ} \mathrm{C}$, and then ubiquinone $(\mathrm{Q} 10)$ was added to a solution of ethanol. Biochars were suspended in $0.1 \mathrm{M} \mathrm{KCl}$ and $0.1 \mathrm{M}$ phosphate buffer, $\mathrm{pH}$, were reduced by addition of borohydride $\left(\mathrm{NaBH}_{4}\right)$, and then subsequently re-oxidized by $\mathrm{O}_{2}$ in air. Changes in the biochar redox states were determined by electrochemical analysis of untreated, $\mathrm{NaBH}_{4}$-reduced, and re-oxidized chars. The redox states of the biochars were quantified by mediated electrochemical reduction (MER) and oxidation (MEO) using an electrochemical cell. A glassy carbon cylinder served both as the working electrode (WE) and electrochemical reaction vessel and the counter electrode was a coiled platinum wire separated from 
the WE compartment by a porous glass frit. The applied redox potentials were measured against $\mathrm{Ag} / \mathrm{AgCl}$ reference electrodes.

A commonly used technique for measuring the redox characteristics of carbons is solid-state cyclic voltammetry (SSCV) [24]. In this technique, a composite electrode consisting of $10 \%$ biochar and $90 \%$ SFG6 graphite (Timcal) was prepared through light grinding in a mortar and pestle. This was mixed with a phosphate buffer, equilibrated for $16 \mathrm{~h}$ and then transferred to a stainless steel cup cell in which the cylindrical walls are Teflon-lined. This mix was compacted in a hydraulic press to produce a working electrode. A stainless steel inner lining was used as the counter electrode. The cell was then allowed to equilibrate with the electrolyte for $1 \mathrm{~h}$ after which the working electrode potential was swept from its open circuit value cathodically to $-1.2 \mathrm{~V}$, after which the sweep was reversed to an upper potential limit of $0.2 \mathrm{~V}$, and then back down again to $-1.2 \mathrm{~V}$. The potential sweep rate was set at $0.05 \mathrm{mV} / \mathrm{s}$. More details are provided in the supplementary information (S1). In this study, the residual electrode, after cycling, was examined using both a scanning electron microscope (SEM) and a transmission electron microscope (TEM) as per the methods described [5]. In this present study and the supplementary information, SEM imaging was carried out using an Hitachi S3400 fitted with a Bruker Silicon Drift Energy Dispersive X-ray microanalysis system (EDS) for elemental analysis and a JEOL 2100 TEM fitted with an Oxford Instruments EDS detector.

Chen et al. [9] determined the electrical conductivities of biochar by two-probe electrical conductance measurements using two gold electrodes separated by a $50 \mu \mathrm{m}$ non-conductive gap. Biochar was placed between the two gold electrodes to bridge the non-conductive gap. Voltage was then scanned from $0 \mathrm{~V}$ to $10.05 \mathrm{~V}$ in steps of $0.025 \mathrm{~V}$. For each sample, current was measured $100 \mathrm{~s}$ after setting the voltage to allow the exponential decay of the transient ionic current in the gap and to measure steady state electronic current.

Husson et al. [25] and [26] note that accurately determining Eh in soils both with and without biochar is difficult, due to:

(i) High variability of soil Eh in space and time: Eh is largely influenced by hydric conditions (water activity), temperature, microbial activity and respiration of living organisms [27,28]. As a consequence, it is difficult to obtain stable measurements, especially in soils with low poising ability (that is, soils with low organic matter and clay content).

(ii) Irreversibility of redox reactions at the surface of the electrodes, which makes it difficult to conduct Eh measurements over long time periods [29].

(iii) Chemical disequilibrium in soils [30].

(iv) Polarisation of and/or leakage from electrodes.

Recently, the possibilities of further complications in Eh measurements were reported [31,32], namely:

(v) The influence of electromagnetic fields on water and living organisms, which can greatly perturb Eh measurements in soil samples through an induced current in the electrode [31].

(vi) The possible role of "structured" interfacial water in cells, affecting electron activity in exclusion zones $[32,33]$. 
In both field and bench scale measurements, tandem Eh-pH measurements should be undertaken to help elucidate the role of biochar in affecting redox processes. Husson et al. [25] recommends that all measurements be undertaken away from electromagnetic fields (as these can affect the stability of final measurement of the voltage) using very high impedance voltmeters and frequent cleaning of electrodes. Multiple sampling is necessary, as if the electrode touches the biochar in the soil, readings could be much lower than in the overall biochar/soil system. In aerobic soils, stable reproducible Eh measurements need to be carried out at a soil moisture content close to field capacity [25].

For bench scale measurements, soil sample preparation needs to be standardized (especially soil drying and rewetting procedure) and temperature must be maintained at approximately $25^{\circ} \mathrm{C}$ [25]. Drying the sample at $35{ }^{\circ} \mathrm{C}$ over 3-4 days led to more stable measurements. They found that approximately $10 \%-15 \%$ of water should be added to sandy soils and $25 \%-35 \%$ for clayey soils. When rewetting, water should have an Eh of approximately $400 \mathrm{mV}$ to ensure reproducible results. In flooded soils, the Eh needs to be measured as a function of depth away from electromagnetic fields with frequent cleaning of the electrode and multiple sampling in the experimental plots.

The following section presents new data using the cyclic voltammetry and soil methods described above.

\subsection{Electrochemical Properties of Biochar as Measured Using Solid State Cyclic Voltammetry} (SSCV), SEM and TEM

Three very different biochars that had been fully characterized and used in field trials were selected. These included:

(1) A wood biochar (Jarrah) produced at $600{ }^{\circ} \mathrm{C}$ in a vertical retort [34]. This biochar had a high surface area, high fixed $\mathrm{C}$, high concentration of stable aromatic $\mathrm{C}$ and low concentration of functional groups and low ash.

(2) Acacia saligna biochar produced at $380{ }^{\circ} \mathrm{C}$ in a rotating drum kiln. This biochar has high labile $\mathrm{C}$ content and a relative low surface area compared with the Jarrah biochar [35].

(3) Chicken litter high mineral ash biochar produced at $400{ }^{\circ} \mathrm{C}$ in a rotating drum kiln [4].

The voltammogram from these biochars was compared to that of the black $\mathrm{C}$ particles taken from Terra Preta soils in the Hata Hara region of the Amazon and examined in detailed by [36]. These particles contain high concentrations of mineral matter and an Fe content of approximately $3 \%$.

The voltammetric behaviour of the Saligna and Jarrah biochar electrodes is shown in Figure 1. The initial sweep from the open circuit potential for both the Saligna and Jarrah down to $-1.2 \mathrm{~V}$ and then back up to $+0.2 \mathrm{~V}$ shows the electrodes behave like a capacitor, with no real evidence for any faradaic charge transfer processes. However, when the upper potential limit is reached, the Saligna electrode undergoes a substantial activation process at a potential that would be typical of the Eh for many soils, in which case there is significant anodic current generated in the potential range from $+0.25 \mathrm{~V}$ to $-0.1 \mathrm{~V}$. This is followed by significant cathodic current at potentials below $-0.7 \mathrm{~V}$. A similar activation process did not occur for the Jarrah biochar. 


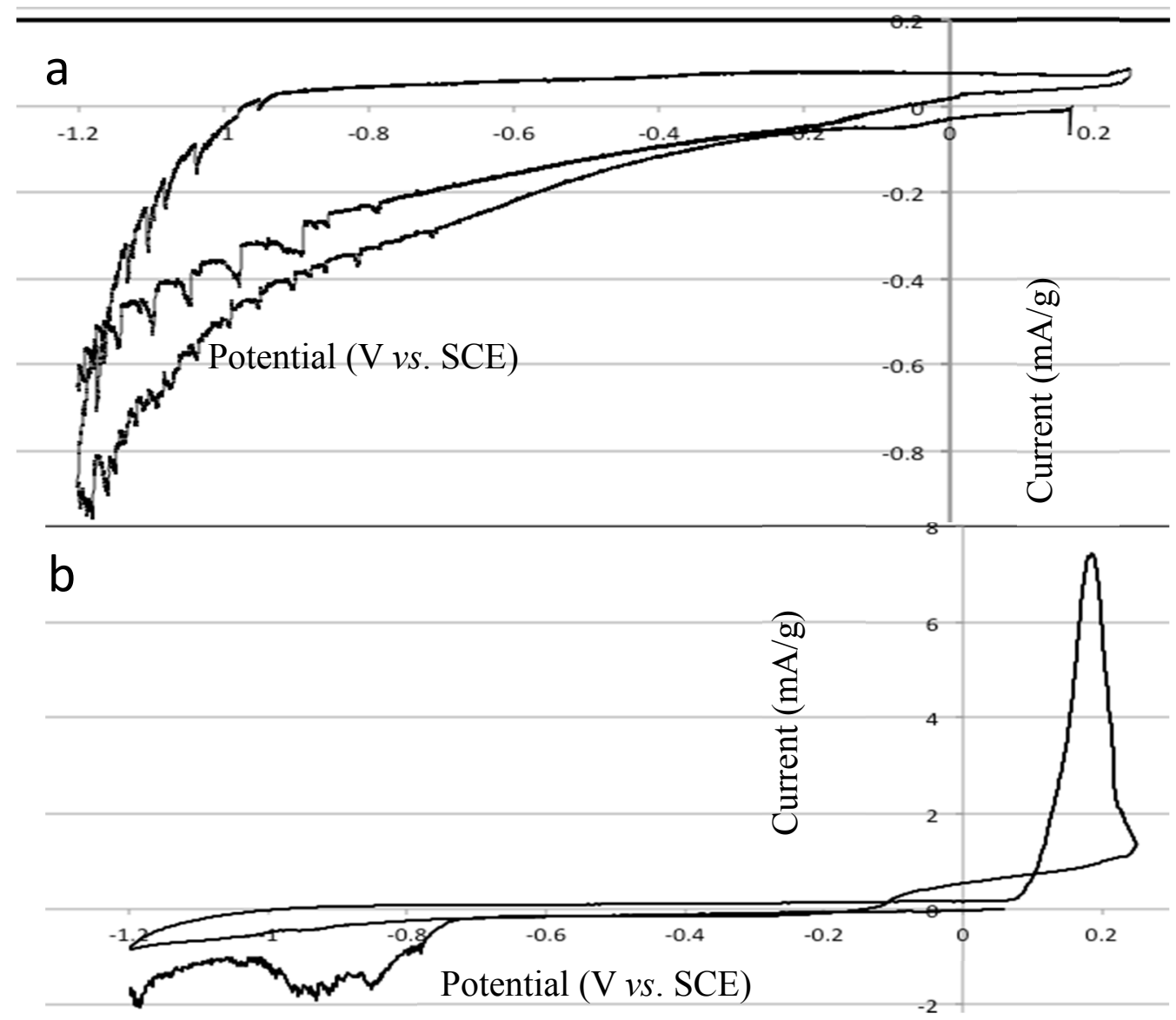

Figure 1. (a) Voltammograms of Jarrah biochar produced at $600{ }^{\circ} \mathrm{C}$; and (b) Acacia saligna biochar produced at $380^{\circ} \mathrm{C}$.

A similar voltammogram was observed when either a chicken manure biochar (Figure 2a) or Terra Preta soil was cycled (Figure 2b). Nakamura et al. [37] and [24] reported that the increase in current would indicate that oxidation of the $\mathrm{C}$ to $\mathrm{CO}_{2}$ takes place preferentially at the nanophase mineral/C interfaces and areas where high concentrations of oxygen functional groups exist [38]. Tulloch et al. [24] using cyclic voltammetry has shown that anatase, pyrite, kaolin montmorillinite and alumina increased the rate of oxidation of $\mathrm{C}$ in coal. Corrosion experiments carried out on graphite and amorphous $\mathrm{C}$ indicate that oxidation of amorphous $\mathrm{C}$ surfaces results in an increase in pore surface area [38]. 


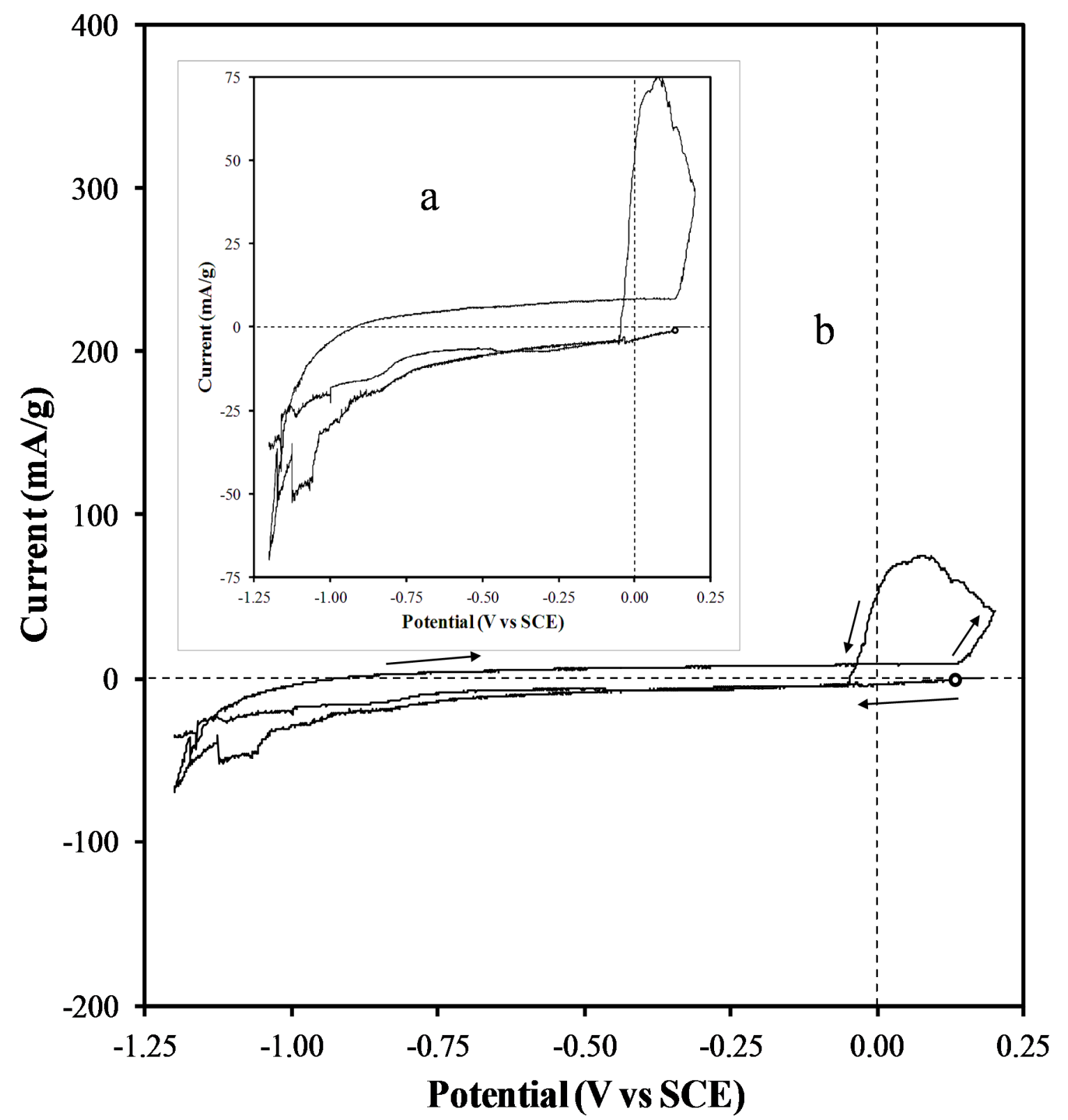

Figure 2. (a) Voltammogram of chicken manure biochar produced at $400{ }^{\circ} \mathrm{C}$; (b) is that of particles of Terra Preta soils taken from Hata Hara district.

The SEM images and EDS spectra from the cycled Acacia Saligna biochar are consistent with the findings above. Significant damage occurred on the surfaces of $\mathrm{C}$ matrix (Figure 3a,b) indicated by broken and rounded edges of the walls of the pores and formation of the cracks around an area rich in Fe-based compounds (Figure 3c). 


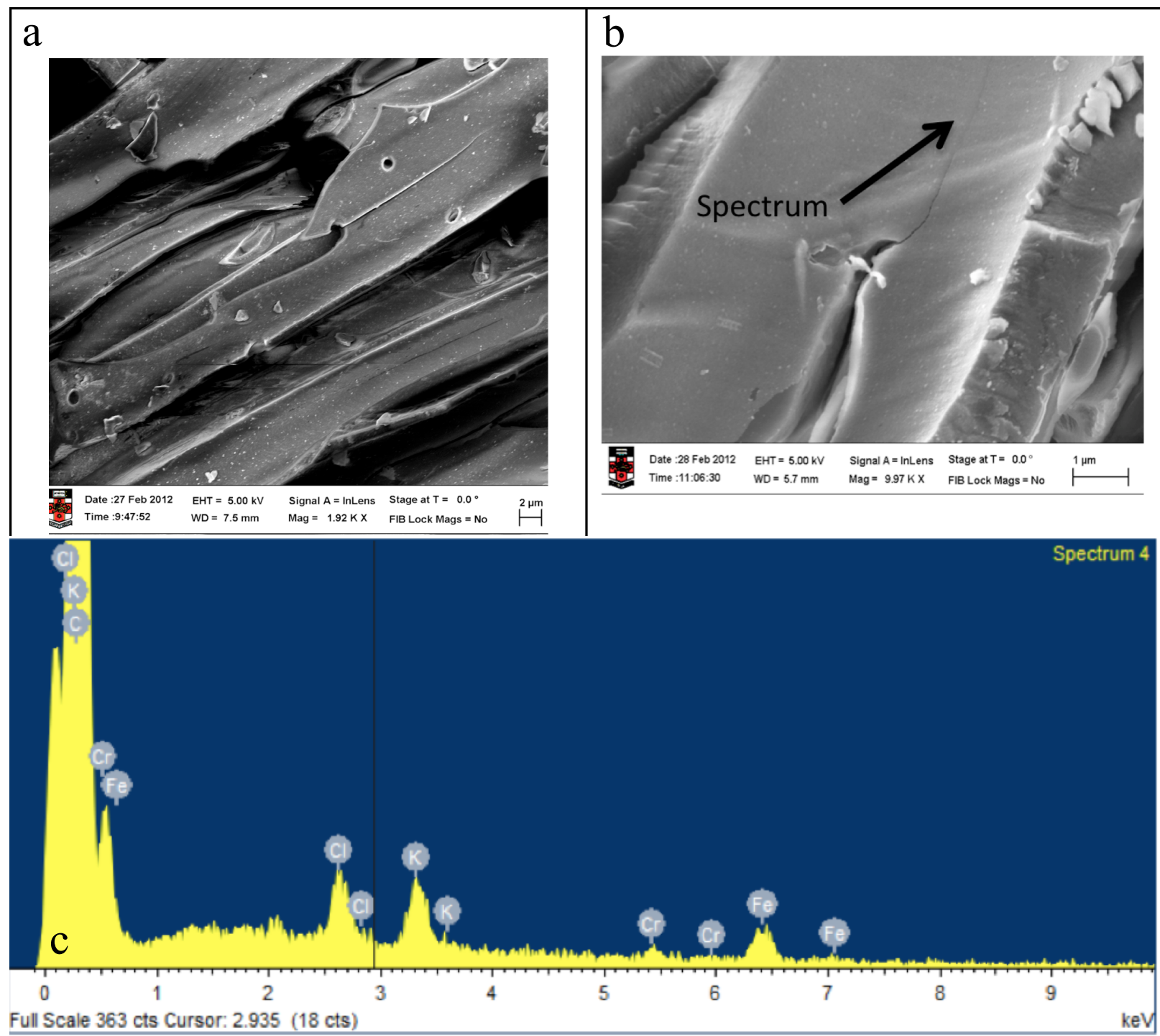

Figure 3. (a) SEM image of a surface of a Acacia Saligna biochar where there has been damage on the walls of the biohar (b) SEM image of the cracks forming in the carbon matrix of the Acacia Saligna biochar; (c) is an EDS analysis of the area shown in (b) indicating that there are localised concentrations of Fe-rich and $\mathrm{KCl}$ phases on this surface.

The damage noted in these images is similar to that reported by [39]. Formation of cracks in the $\mathrm{C}$ matrix could be due to the evolution of gas (probably $\mathrm{CO}_{2}$ ), especially as they occur in regions where there is a high concentration high in Fe and $\mathrm{O}$ [40]. TEM examination of the surface of the cycled Saligna biochar revealed the formation of a crack at the end of an Fe-rich mineral phase (Figure 4a-c). Figure 5 shows a TEM image of nanophase $\mathrm{Fe} / \mathrm{C} / \mathrm{O}$ rich particles that were separated from the main biochar particle. The nanophase Fe particles are coated with an amorphous $\mathrm{C}$ layer. These structures are similar to those observed by [41] on corroded carbon black samples. 

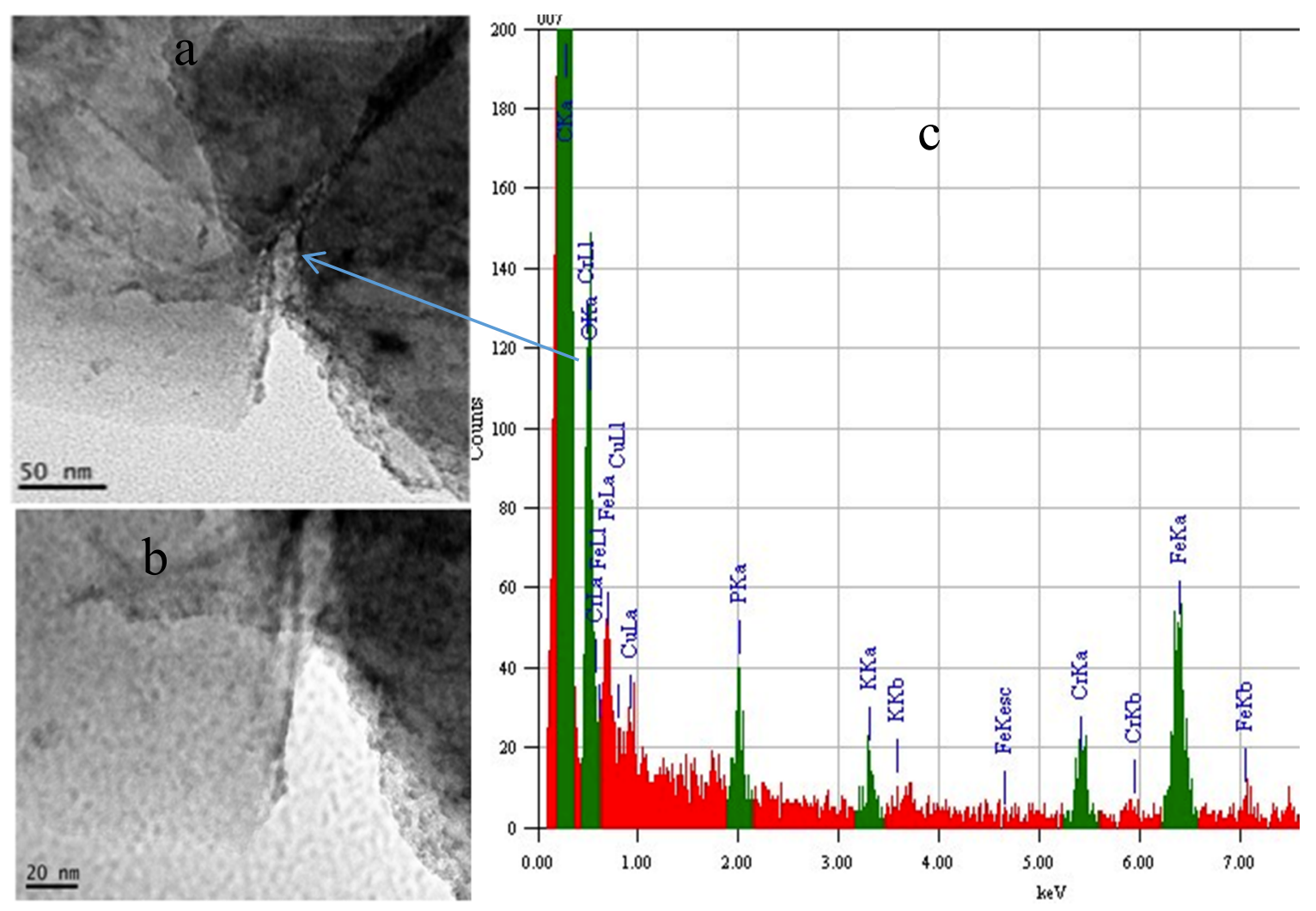

Figure 4. (a) TEM image of the oxidized surface of the Saligna biochar where the light coloured region is amorphous carbon and the darker areas are Fe-rich minerals; (b) is a magnified TEM image of the crack arrowed in Figure 5a,c; (c) is an EDS spectrum taken from the area around the crack.

Similar TEM and SEM images of the Jarrah biochar (Figure S2) with its high concentration of graphitic planes did not reveal similar damage to the surfaces after cycling two times. It is thus apparent that this high temperature wood biochar is much more resistant to oxidation than the lower temperature biochar. These results thus correspond to evidence that higher HTT biochars are more stable in the environment and have substantially longer predicted half-lives than lower HTT biochars [42].

It is possible that once the labile organic $\mathrm{C}$ has been oxidized, new oxide layers on more stable graphene sheets could form, and these could protect the surface from further oxidation [43]. These types of processes could account for some of the results from incubation studies where biochar addition causing short-term positive priming of soil organic matter [44] and then longer term negative priming [45]. Whether biotic processes have a larger role than these chemical redox reactions is yet to be determined. 


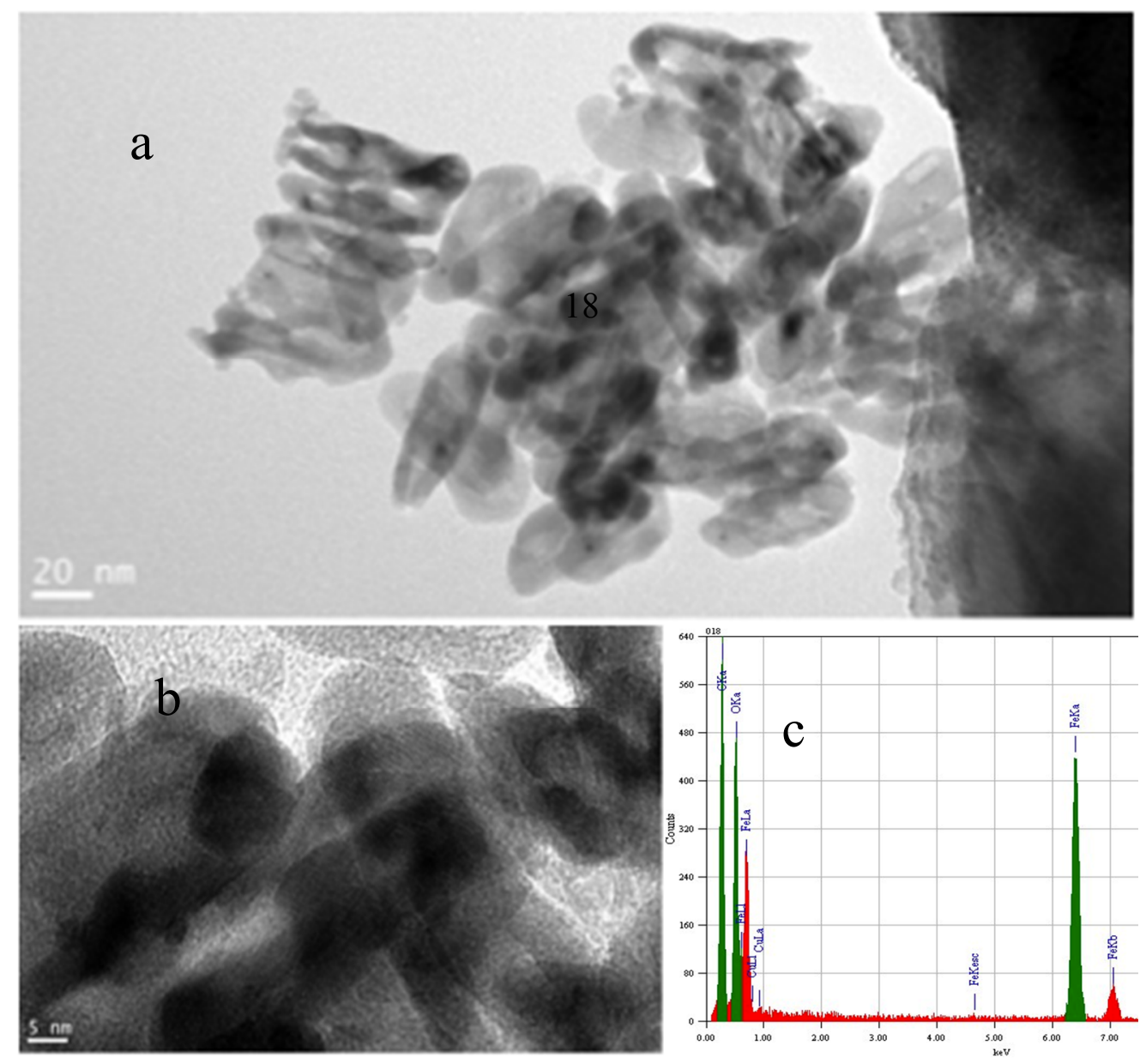

Figure 5. (a) shows a TEM image of the surface of biochar after cycling; (b) is a higher resolution image of the area shown in (a) (18) and (c) is an EDS spectrum from area 18 in (a).

\subsection{Changes in Eh and $p H$ When Biochars are Added to Soil Using the In-Situ} Measurement Technique

Joseph et al. [4,5] and [17] have detailed the potential biotic and abiotic redox reactions that take place when biochar is added to soil. Figure 6 summarises that data on a modified Pourbaix diagram in the changes of $\mathrm{Eh}\left(\mathrm{pH}\right.$ corrected) and $\mathrm{pH}$ after rice straw biochar (RSB) produced at $400{ }^{\circ} \mathrm{C}$ and $625{ }^{\circ} \mathrm{C}$ were added to a sandy soil (arenosol, $92 \%$ sand, $2 \%$ silt, $6 \%$ clay) at application rates of $0.5 \%$, $1 \%, 2 \%$ and $5 \mathrm{wt} \%$. Detailed data for this biochar including Eh-corrected for $\mathrm{pH}$ are given in supplementary information (Figure S3a-c).

Adding a $1 \mathrm{wt} \% \mathrm{RSB}$ produced at either $400{ }^{\circ} \mathrm{C}$ or $650{ }^{\circ} \mathrm{C}$ reduced the soil Eh from $0.55 \mathrm{~V}$ to $0.38 \mathrm{~V}$ and the $\mathrm{pH}$ was increased from 4.6 to 6.0. These conditions are considered to be very favourable for the growth of most plants and for the increase in beneficial micro-organisms [8,10,46]. Adding a small amount ( $2 \mathrm{wt} \%$ ) of either temperature RSB reduces the soil Eh from $0.675 \mathrm{~V}$ to $0.325 \mathrm{~V}$ and the $\mathrm{pH}$ was increased from 4.6 to 6.9. Similarly, if the Eh is normalised for a $\mathrm{pH}$ of 7 (see supplementary information), the effect of adding 5\% biochar does not significantly reduce Eh compared with adding $2 \%$. A similar set of results were obtained for rice husk biochar, although $\mathrm{pH}$ was not increased to the same extent as with the straw biochar, due to the high mineral silica content and lower carbonate value 
(Figure S4a,4b,4c,4d). A low Eh may affect $\mathrm{N}$ and $\mathrm{P}$ dynamics, alter the diversity and/or abundance of micro-organisms, and, in turn, affect the growth of certain plants and change the emissions of $\mathrm{N}_{2} \mathrm{O}$ and $\mathrm{CH}_{4}$ [47].

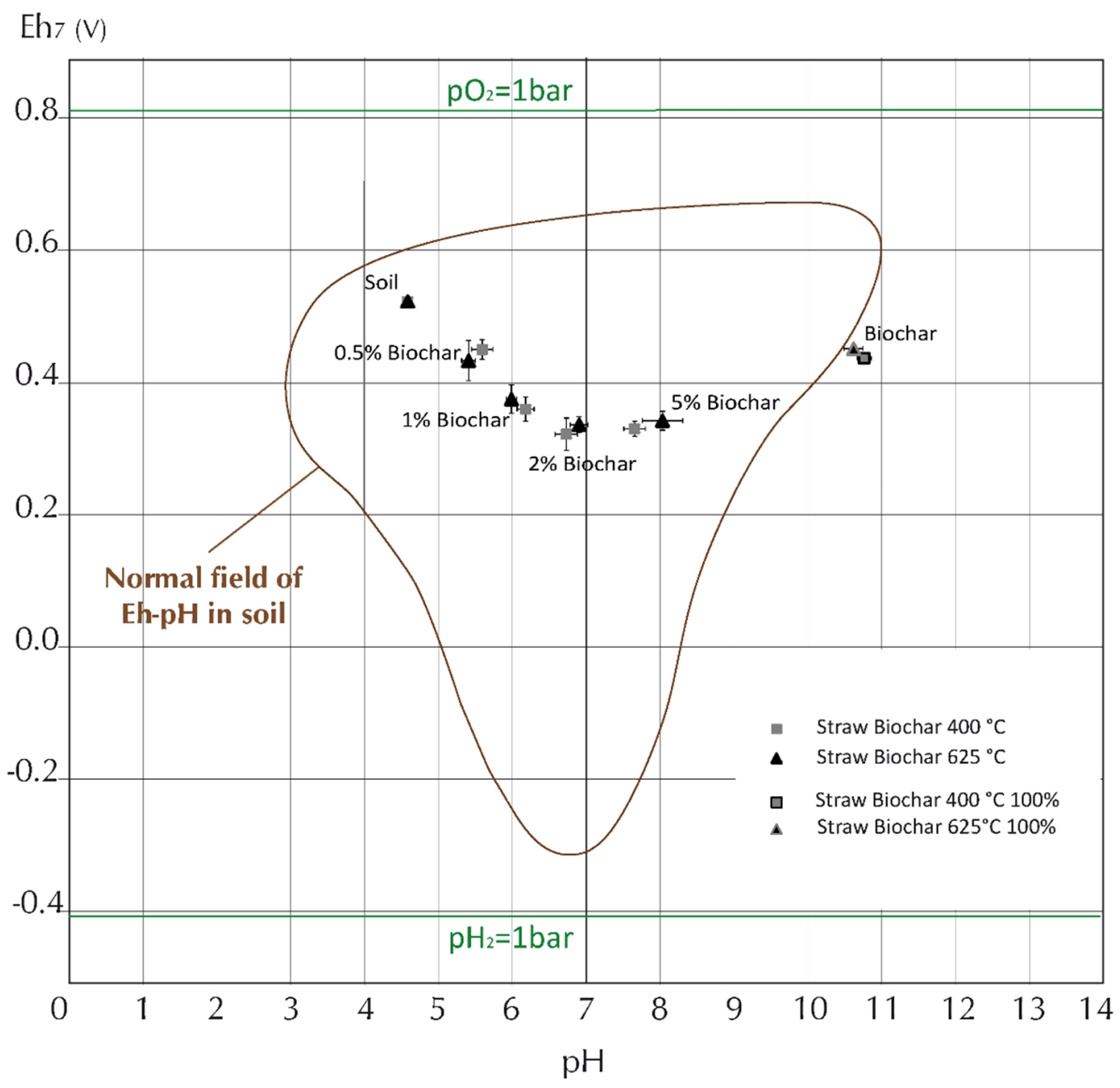

Figure 6. Summary of information on measurement on the change in Eh (corrected for $\mathrm{pH}$ ) and $\mathrm{pH}$ with the addition of 2 rice straw biochars produced at $400{ }^{\circ} \mathrm{C}$ and $625^{\circ} \mathrm{C}$.

\section{Conclusions and Future Directions}

The initial investigations discussed above along with the work of $[2-5,10,13,48,49]$ highlight the importance of redox process affecting the bulk soil properties occurring on the surface and in the vicinity of biochar particles. When biochars are added to soils in significant quantities, we sometimes observe a rapid change in both $\mathrm{Eh}$ and $\mathrm{pH}$. The magnitude of the changes that occur for a particular soil/biochar combination are a function of the pyrolysis process conditions (time and maximum temperature), the feedstock, whether there has been any pre or post-treatment of the biochar, and on the soil type and environment. Mineral matter, labile organic molecules and $\mathrm{C}$ functional groups at surfaces determine the Eh of a biochar and this, in turn, affects the change in Eh of a soil after the amendment. As [30] noted, redox processes in soil are kinetically hindered and are in disequilibrium with each other. Thus biochar impacts on soil Eh can change over time especially if biochar 
reacts/interacts with micro-organisms, soil mineral and organic matter, chemical fertilisers and plant roots. As [4] noted, the redox activity of biochars in soils could be a function of the changes in the nature of the organomineral layers that form and/or break down during different crop cycles, changes in environmental conditions and through movement through the soil profile. It is possible that as biochars themselves fragment, new redox active surfaces are exposed, thus resulting in a more complex series of redox reactions.

Key questions that require further research include:

1. Are the redox properties of biochars responsible for some or any of the different effects that biochars have been reported to have in the integrated soil/plant/rhizosphere microbiome system?

2. What are the mutual redox interactions of different biochars in soils of different types?

3. Do biochars increase the poising capacity of soils and why?

4. Are some biochars more effective than others in altering Eh fluctuations, especially in systems (e.g., rice) where flooding and drying cycles occur?

5. Does the penetration of root hairs into the pores of biochar and/or the attachment of roots to the biochar surface change the potential across the plant cell wall and change the take up of specific nutrients? If so, why does this occur?

6. Do Fe and Mn/Oxide particles with diameters less than $20 \mathrm{~nm}$ redox active particles on the surfaces of biochar assist in the breakdown of organic matter, increase $\mathrm{P}$ availability and reduce the production of greenhouse gases?

Studies to answer such questions have yet to be undertaken, in part because the recognition that biochars are redox active is relatively recent, and, in part, due to the difficulties involved in designing experiments to isolate and test these questions. We propose that one way to do this would be to compare soil system impacts of a given biochar with those of the same biochar doped with redox active components or otherwise altered in its redox activity. Alternatively, the creation of a model system that isolates effects of interest and reduces the number of potential causative factors could be developed and tested.

\section{Acknowledgments}

We acknowledge the help of the Electron Microscope and X-ray unit of University of Newcastle and the Electron Microscope Unit of the University of NSW. This work was supported by the grant LP120200418 of the ARC, Renewed Carbon Pty Ltd. and the DAFF Carbon Farming Futures Filling the Research Gap (RG134978).

\section{Author Contributions}

All authors have contributed to the production of this paper.

\section{Conflicts of Interest}

The authors have no conflict of interest. 


\section{References}

1. Lehmann, J.; Joseph, S. Biochar for Environmental Management: Science, Technology and Implementation; Routledge: Abingdon, UK, 2015.

2. Graber, E.; Tschansky, L.; Cohen, E. Reducing capacity of water extracts of biochars and their solubilization of soil Mn and Fe. Eur. J. Soil Sci. 2014, 65, 162-172.

3. Klüpfel, L.; Keiluweit, M.; Kleber, M.; Sander, M. Redox properties of plant biomass-derived black carbon (biochar). Environ. Sci. Technol. 2014, 48, 5601-5611.

4. Joseph, S.D.; Camps-Arbestain, M.; Lin, Y.; Munroe, P.; Chia, C.H.; Hook, J.; van Zweiten, L.; Kimber, S.; Cowie, A.; Singh, B.P.; et al. An investigation into the reactions of biochars in soil. Aust. J. Soil Res. 2010, 48, 501-515.

5. Joseph, S.; Graber, E.R.; Chia, C.; Munroe, P.; Donne, S.; Thomas, T.; Nielsen, S.; Marjo, C.; Rutlidge, H.; Pan, G.X.; et al. Shifting paradigms on biochar: Micro/nano-structures and soluble components are responsible for its plant-growth promoting ability. Carbon Manag. 2013, 4, 323-343.

6. Bartlett, R.J.; James, B.R. Redox chemistry of soils. Adv. Agron. 1993, 50, 151-208.

7. Li, Y.R.; Yu, S.R.; Strong, J.; Wang, H. Are the biogeochemical cycles of carbon, nitrogen, sulfur, and phosphorus driven by the "FeIII-FeII redox wheel" in dynamic redox environments? J. Soils Sediments 2012, 12, 683-693.

8. Chesworth, W. Redox, soils, and carbon sequestration. Edafología 2004, 11, 37-43.

9. Chen, S.; Rotaru, A.; Shrestha, P.; Malvankar, S.; Liu, F.; Fan, W.; Nevin, K.P.; Lovley, D.R. Promoting interspecies electron transfer with biochar. Sci. Rep. 2014, 4, 5019.

10. Husson, O. Redox potential (Eh) and $\mathrm{pH}$ as drivers of soil/plant/microorganism systems: A transdisciplinary overview pointing to integrative opportunities for agronomy. Plant Soil 2013, 362, 389-417.

11. Pidello, A. Environmental redox potential and redox capacity concept using a simple polarographic experiment. J. Chem. Educ. 2003, 80, 68-70.

12. Glinski, J.; Stepniewski, W. Soil Aeration and its Role for Plants; CRC Press: Boca Raton, FL, USA, 1985.

13. Van Zwieten, L.; Kammann, C.; Cayuela, M.L.; Singh, B.-P.; Joseph, S.; Kimber, S.; Clough T.; Spokas, K. Biochar Effects on Nitrous Oxide and Methane Emissions from Soil. In Biochar for Environmental Management: Science, Technology and Implementation; Lehmann, J., Joseph, S., Eds.; Routledge: Abingdon, UK, 2015.

14. Davidson, E.A.; Dail, D.B.; Chorover, J. Iron interference in the quantification of nitrate in soil extracts and its effect on hypothesized abiotic immobilization of nitrate. Biogeochemistry 2008, 90, 65-73.

15. Yin, X.; Lv, X.; Jiang, M.; Zou, Y. Research progress of the coupling process of Fe and $\mathrm{N}$ in wetland soils. Chin. J. Environ. Sci. 2010, 31, 2254-2259. (In Chinese)

16. Melton, E.; Swanner, E.D.; Behrens, S.; Schmidt, C.; Kappler, A. The interplay of microbially mediated and abiotic reactions in the biogeochemical Fe cycle. Nat. Rev. Microbiol. 2014, 12, 797-808. 
17. Kappler, A.; Wuestner, M.L.; Ruecker, A.; Harter, J.; Halama, M.; Behrens, S. Biochar as an Electron Shuttle between Bacteria and Fe(III) Minerals. Environ. Sci. Technol. 2014, 1, 339-344.

18. Ishihara, S. Recent trend of advanced carbon materials from wood charcoals. Mokuzai Gakkai Shi 1996, 42, 717-723

19. Bourke, J.; Manley-Harris, M.; Fushimi, C.; Dowaki, K.; Nunoura, T.; Antal, M.J. Do all carbonized charcoals have the same chemical structure? 2. A model of the chemical structure of carbonized charcoal. Ind Eng Chem Res. 2007, 46, 5954-5967

20. Arends, J.; Verstraede, W. 100 years of microbial electricity production:three concepts for the future. Microbial Biotech. 2012, 5, 333-346.

21. Fabiano, A.; Petter, B.; Madari, E. Biochar: Agronomic and environmental potential in Brazilian savannah soils. Rev. Bras. Eng. Agríc. Ambient. 2012, 16, 761-768.

22. Suda, F.; Matsuo, T.; Ushioda, D. Transient changes in the power output from the concentration difference cell (dialytic battery) between seawater and river water. Energy 2007, 32, 165-173.

23. Van Zwieten, L.; Kimber, S.; Morris, S.; Chan, K.Y.; Downie, A.; Rust, J.; Joseph, S.; Cowie, A. Effects of biochar from slow pyrolysis of papermill waste on agronomic performance and soil fertility. Plant Soil 2010, 327, 235-246.

24. Tulloch, J.; Allen, J.; Wibberley, L.; Donne, S. Influence of selected coal contaminants on graphitic carbon electro-oxidation for application to the direct carbon fuel cell. J. Power Sources 2014, 260, 140-149.

25. Husson, O.; Huson, B.; Brunet, A.; Babre, D.; Alary, K.; Sarthou, J.; Charpentier, H.; Durand, M.; Benada, J.; Henry, M. Practical improvements in soil redox potential (Eh) measurement for characterisation of soil properties. Application for comparison of conventional and conservation agriculture cropping systems. Anal. Chim. Acta 2015, under review.

26. Fiedler, S.; Vepraskas, M.J.; Richardson, J.L. Soil redox potential: Importance, field measurements, and observations. Adv. Agron. 2007, 94, 1-54.

27. Thomas, C.R.; Miao, S.L.; Sindhoj, E. Environmental factors affecting temporal and spatial patterns of soil redox potential in Florida Everglades wetlands. Wetlands 2009, 29, 1133-1145.

28. Benada, J. A non invasive method for redox potential measurement. Obilnarske Listy 2009, 14, $15-18$.

29. Whitfield, A.E.; Ullman, D.E.; German, T.L. Tomato spotted wilt virus glycoprotein $\mathrm{G}(\mathrm{C})$ is cleaved at acidic pH. Virus Res. 2005, 110, 183-186.

30. Grundl, T. A review of current understanding of redox capacity in natural, disequilibrium systems. Chemosphere 1994, 28, 613-626.

31. Colic, M.; Morse, D. The elusive mechanism of the magnetic "memory" of water. Colloids Surf. A: Physicochem. Eng. Asp. 1999, 154, 167-174.

32. Del Giudice, E.; Spinetti, P.R.; Tedeschi, A. Water dynamics at the root of metamorphosis in living organisms. Water 2010, 2, 566-586.

33. Pollack, G.; Clegg, J. Unexpected Linkage between Unstirred Layers, Exclusion Zones, and Water, In Phase Transitions in Cell Biology; Pollack, G., Chin, W.C., Eds.; Springer Netherlands: Dordrecht, The Netherlands, 2008; pp. 143-152. 
34. Nielsen S.; Minchin T.; Kimber S.; van Zwieten, L.; Caporaso, G.; Gilbert, J.; Munroe, P.; Joseph, S.; Thomas, T. Enhanced biochar causes complex shifts in soil microbial communities. Agric. Ecosyst. Environ. 2014, 191, 73-82.

35. Chia, C.H.; Singh, B.P.; Joseph, S.; Graber, E.; Munroe, P. Characterization of an enriched biochar. J. Anal. Appl. Pyrolysis 2014, 108, 26-34.

36. Liang, B.; Lehmann, J.; Solomon, D.; Kinyangi, J.; Grossman, J.; O’Neill, B.; Skjemstad, J.O.; Thies, J.; Luizão, F.J.; Petersen, J.; et al. Black carbon increases cation exchange capacity in soils. Soil Sci. Soc. Am. J. 2006, 70, 1719-1730.

37. Nakamura, M.; Nakanishi, M.; Yamamoto, K. Influence of physical properties of activated carbons on characteristics of electric double-layer capacitors. J. Power Sources 1996, 60, 225-231.

38. Gallagher, K.G.; Fuller, T.F. Kinetic model of the electrochemical oxidation of graphitic carbon in acidic environments. Phys. Chem. Phys. 2009, 11, 11557-11567.

39. Siroma, Z.; Ishii, Z.; Yasuda, K.; Miyazaki, Y.; Inaba, M.; Tasaka, A. Imaging of highly oriented pyrolytic graphite corrosion accelerated by Pt particles. Electrochem. Commun. 2005, 7, 1153-1156.

40. Willsau, J.; Heitbaum, J. The influence of Pt-activation on the corrosion of carbon in gas diffusion electrodes-A dems study. Electroanal. Chem. 1984, 161, 93.

41. Liu, Z.Y.; Zhang, J.L.; Yu, P.T.; Zhang, J.X.; Makharia, R.; More, K.L.; Stach, E.A. Transmission Electron Microscopy Observation of Corrosion Behaviors of Platinized Carbon Blacks under Thermal and Electrochemical Conditions. J. Electrochem. Soc. 2010, 157, B906-B913.

42. Crombie, K.; Mašek, O.; Sohi, S.; Brownsort, P.; Cross, A. The effect of pyrolysis conditions on biochar stability as determined by three methods. GCB Bioenergy 2013, 5, 122-131.

43. Youngmi, Y. Study on the degradation of carbon materials for electrocatalytic applications. Ph.D. Thesis, Technical University of Berline, Berlin, Germany, 2014.

44. Maestrini, B.; Herrmann, A.M.; Nannipieri, P.; Schmidt, M.W.I.; Abiven, S. Ryegrass-derived pyrogenic organic matter changes organic carbon and nitrogen mineralization in a temperate forest soil. Soil Biol. Biochem. 2014, 69, 291-301.

45. Zimmerman, A.R.; Gao, M.; Ahn, M.Y. Positive and negative carbon mineralization priming effects among a variety of biochar-amended soils. Soil Biol. Biogeochem. 2011, 43, 1169-1179.

46. Baas Becking, L.G.M.; Kaplan, I.R.; Moore, D. Limits of the natural environment in terms of pH and oxidation-reduction potentials. J. Geol. 1960, 68, 243-284.

47. Kirk, G. The Biogeochemistry of Submerged Soils; John Wiley \& Sons: Chichester, UK, 2004; pp. 92-134.

48. Singla, A.; Iwasa, H.; Inubushi, K. Effect of biogas digested slurry based-biochar and digested liquid on $\mathrm{N}_{2} \mathrm{O}, \mathrm{CO}_{2}$ flux and crop yield for three continuous cropping cycles of komatsuna (Brassica rapa var. perviridis). Biol. Fertil. Soils 2014, 50, 1201-1209. 
49. Singla, A.; Dubey, S.K.; Singh, A.; Inubushi, K. Effect of biogas digested slurry-based biochar on methane flux and methanogenic archaeal diversity in paddy soil. Agric. Ecosyst. Environ. 2014, $197,278-287$.

(C) 2015 by the authors; licensee MDPI, Basel, Switzerland. This article is an open access article distributed under the terms and conditions of the Creative Commons Attribution license (http://creativecommons.org/licenses/by/4.0/). 